\title{
Transition temperature in KDP type crystals under external pressures. Role of H-bond geometry
}

\author{
R.R.Levitskii ${ }^{1}$, A.P.Moina ${ }^{1}$, I.R.Zachek ${ }^{2}$ \\ 1 Institute for Condensed Matter Physics \\ of the National Academy of Sciences of Ukraine, \\ 1 Svientsitskii Str., 79011 Lviv, Ukraine \\ 2 State University "Lviv Polytechnics", \\ 13 Bandery Str., 290000, Lviv, Ukraine
}

Received October 4, 1998

Within the four-particle cluster approximation for the proton ordering model, we study effects of external pressures which do not lower the symmetry of crystals on deuterated ferroelectrics and antiferroelectrics of $\mathrm{KH}_{2} \mathrm{PO}_{4}$ family. We show that the universality of the transition temperature vs Dsite distance dependence observed experimentally in some of the crystals deformed by hydrostatic pressure is also obeyed by the other crystals of the family as well as under the uniaxial pressure $p=-\sigma_{3}$.

Key words: $K D P$, pressure, $D$-site distance, transition temperature

PACS: $77.84 . F a$

Potassium dihydrogen phosphate $\mathrm{KH}_{2} \mathrm{PO}_{4}$ (KDP) is a prototype for a family of hydrogen bonded crystals undergoing ferroelectric or antiferroelectric structural phase transitions. When the results of Raman scattering experiments [1] raised serious doubts about the validity of the proton ordering (or tunnelling) model, which for years had been generally accepted as the established basis for describing these phase transitions, the explanation by this model of the observed in these crystals increase in the transition temperature with deuteration (isotope effect) by a decrease in tunnelling integral as far as protons are replaced with deuterons, was excluded, too. If the tunnelling model is discarded, the isotope effect is accounted for within the theory of the so-called geometric isotope effect [2] where the shift in the transition temperature with deuteration is attributed to the changes in the geometry of hydrogen bonds, namely, to an increase in the separation $\delta$ between two possible hydrogen sites on a bond and/or in H-bond length.

Hence, even though the high pressure studies are not able to unambiguously establish the mechanisms of the phase transitions, they come to be extremely im- 
portant as far as they are the only means to continuously vary the parameters of hydrogen bonds and happen to be the best tool to study the dependencies of crystal characteristics on the H-bond geometry and explore its role in the physics involved. For instance, by means of high pressure research, the universality of the dependence of transition temperature on $\mathrm{H}$-site distance has been established [3] for four crystals of this family having a three dimensional network of hydrogen bonds, namely, KDP, $\mathrm{KD}_{2} \mathrm{PO}_{4}, \mathrm{NH}_{4} \mathrm{H}_{2} \mathrm{PO}_{4}$, and $\mathrm{ND}_{4} \mathrm{D}_{2} \mathrm{PO}_{4}$.

Since the tunnelling model still remains the most elaborated and widely used approach to describing the phase transitions in the KDP family crystals, it seems worthwhile to examine its ability to describe the universality of the transition temperature vs $\mathrm{H}$-site distance dependencies observed in $\mathrm{KD}_{2} \mathrm{PO}_{4}$ and $\mathrm{ND}_{4} \mathrm{D}_{2} \mathrm{PO}_{4}$ under hydrostatic pressure. We also verify whether this universality is obeyed by other crystals of this family under hydrostatic or uniaxial pressure.

\section{The model}

We consider a deuteron subsystem of a ferroelectric (FE) or an antiferroelectric (AFE) crystal of $\mathrm{KH}_{2} \mathrm{PO}_{4}$ family with a general formula $\mathrm{MeD}_{2} \mathrm{XO}_{4}$, where $\mathrm{Me}=$ $\mathrm{K}, \mathrm{Rb}, \mathrm{ND}_{4}, \mathrm{X}=\mathrm{P}$, As. The crystals possess the tetragonal symmetry in the paraelectric phase. In our calculations we use the model of strained $\mathrm{KH}_{2} \mathrm{PO}_{4}$ type crystals by Stasyuk et al [4], as well as some ideas of the previous theories by Blinc [5] and Torstveit [6]. In the present work, we consider only pressures which do not lower the system symmetry: hydrostatic or uniaxial $p=-\sigma_{3}$ applied along the ferroelectric axis $c$.

We perform our calculations within the 4-particle cluster approximation which enables us to adequately take into account the strong short-range correlations between deuterons. The 4-cluster Hamiltonian has got the conventional form [7-9]:

$$
\begin{aligned}
H_{q}= & V\left[\frac{\sigma_{q 1}}{2} \frac{\sigma_{q 2}}{2}+\frac{\sigma_{q 2}}{2} \frac{\sigma_{q 3}}{2}+\frac{\sigma_{q 3}}{2} \frac{\sigma_{q 4}}{2}+\frac{\sigma_{q 4}}{2} \frac{\sigma_{q 1}}{2}\right] \\
& +U\left[\frac{\sigma_{q 1}}{2} \frac{\sigma_{q 3}}{2}+\frac{\sigma_{q 2}}{2} \frac{\sigma_{q 4}}{2}\right]+\Phi \frac{\sigma_{q 1}}{2} \frac{\sigma_{q 2}}{2} \frac{\sigma_{q 3}}{2} \frac{\sigma_{q 4}}{2}-\sum_{f=1}^{4} \frac{z_{q f}^{i}}{\beta} \frac{\sigma_{q f}}{2} ;
\end{aligned}
$$

two values of the Ising spin $\sigma_{q f}= \pm 1$ are assigned to two deuteron sites on the $f$-th bond in the $q$-th cell. Fields $z_{q f}^{i}$ include the effective cluster fields $\Delta_{q f}^{i}$ created by the sites neighbouring to the $q f$-th site, and the long-range interactions (dipole-dipole and indirect via lattice vibrations) $J_{f f^{\prime}}\left(q q^{\prime}\right)$ within the mean field approximation. Depending on the choice of the theory parameters, Hamiltonian (1) can describe both the ferroelectric and antiferroelectric ordering.

Constants $V, U$, and $\Phi$, describing the short-range correlations between deuterons, are the following functions of Slater energies $\varepsilon, w$, and $w_{1}$, which are, of course, different for ferro- and antiferroelectrics

$$
\begin{array}{ll}
\text { FE : } & V=-\frac{w_{1}}{2}, \quad U=-\varepsilon+\frac{w_{1}}{2}, \quad \Phi=4 \varepsilon-8 w+2 w_{1} ; \\
\underline{\mathrm{AFE}}: & V=\frac{\varepsilon-w_{1}}{2}, \quad U=\frac{\varepsilon+w_{1}}{2}, \quad \Phi=2 \varepsilon-8 w+2 w_{1} .
\end{array}
$$


The Slater energies $\varepsilon, w$, and $w_{1}$ and the long-range interactions $J_{f f^{\prime}}\left(q q^{\prime}\right)$ are proportional to the square of the separation between two possible positions of a deuteron on a bond - D-site distance $\delta$. Assuming the linear dependence of $\delta$ in all $\mathrm{MeD}_{2} \mathrm{XO}_{4}$ crystals on hydrostatic and uniaxial $p=-\sigma_{3}$ pressure (according to [10], the variation of $\delta$ with hydrostatic pressure in $\mathrm{KD}_{2} \mathrm{PO}_{4}$ is linear indeed) $\delta=\delta_{0}+\delta_{1} p$, we expand $\varepsilon, w, w_{1}$, and $J_{f f^{\prime}}\left(q q^{\prime}\right)$ in powers of pressure $p$ up to the linear terms (expressing $p$ via the resulting strain $\varepsilon_{1}+\varepsilon_{2}+\varepsilon_{3}$ ). Other mechanisms of pressure influence the energy parameters of the model, like, for instance, electrostriction. So, the changes in distances between the dipoles due to the lattice deformation are taken into account by expanding $\varepsilon, w, w_{1}$, and $J_{f f^{\prime}}\left(q q^{\prime}\right)$ in diagonal components of the strain tensor (which do not split degenerate Slater levels) up to the linear terms, so that

$$
\begin{gathered}
\varepsilon=\varepsilon^{0}\left[1-\frac{2}{S} \frac{\delta_{1}}{\delta_{0}} \sum_{j=1}^{3} \varepsilon_{j}\right]+\sum_{i=1}^{3} \delta_{1 i} \varepsilon_{i}, \quad w=w^{0}\left[1-\frac{2}{S} \frac{\delta_{1}}{\delta_{0}} \sum_{j=1}^{3} \varepsilon_{j}\right]+\sum_{i=1}^{3} \delta_{2 i} \varepsilon_{i}, \\
w_{1}=w_{1}^{0}\left[1-\frac{2}{S} \frac{\delta_{1}}{\delta_{0}} \sum_{j=1}^{3} \varepsilon_{j}\right]+\sum_{i=1}^{3} \delta_{3 i} \varepsilon_{i}, \\
J_{f f^{\prime}}\left(q q^{\prime}\right)=J_{f f^{\prime}}^{(0)}\left(q q^{\prime}\right)\left[1-\frac{2}{S} \frac{\delta_{1}}{\delta_{0}} \sum_{j=1}^{3} \varepsilon_{j}\right]+\sum_{j=1}^{3} \psi_{f f^{\prime}}^{j}\left(q q^{\prime}\right) \varepsilon_{j} .
\end{gathered}
$$

Here $S=\sum_{i j} S_{i j}^{(0)}$ and $S=\sum_{j} S_{3 j}^{(0)}$ for hydrostatic and uniaxial $p=-\sigma_{3}$ pressures, respectively; $S_{i j}^{(0)}$ are elastic compliances. The parameters $\psi_{f f^{\prime}}^{i}\left(q q^{\prime}\right)$ and $\delta_{i j}$ are the same for all the pressures (not lowering the system symmetry) applied to a given crystal, whereas the ratio $\delta_{1} / \delta_{0}$ is different for hydrostatic and uniaxial pressures.

After conventional cluster approach calculations, the thermodynamic potential of strained crystals is obtained $[7,8]$

$$
\begin{aligned}
g^{\mathrm{f}} & =\bar{v} \sum_{i} \varepsilon_{i} p_{i}+\frac{\bar{v}}{2} \sum_{i j} c_{i j}^{(0)} \varepsilon_{i} \varepsilon_{j}-2 w+2 \nu_{\mathrm{c}}(0)\left[\eta^{\mathrm{f}}\right]^{2}+2 T \ln \frac{2}{\left(1-\left[\eta^{\mathrm{f}}\right]^{2}\right) D^{\mathrm{f}}} \\
g^{\mathrm{a}} & =\bar{v} \sum_{i} \varepsilon_{i} p_{i}+\frac{\bar{v}}{2} \sum_{i j} c_{i j}^{(0)} \varepsilon_{i} \varepsilon_{j}-2 w+\varepsilon+2 \nu_{\mathrm{a}}\left(\boldsymbol{k}_{Z}\right)\left[\eta^{\mathrm{a}}\right]^{2}+2 T \ln \frac{2}{\left(1-\left[\eta^{\mathrm{a}}\right]^{2}\right) D^{\mathrm{a}}}
\end{aligned}
$$

indices "f" and "a" stand for "ferroelectrics" and "antiferroelectrics", respectively; $c_{i j}^{(0)}$ are the so-called "seed" elastic constants of a crystal, describing the elasticity of a fictitious lattice without deuterons; $\bar{v}=v / k_{\mathrm{B}} ; v$ is the unit cell volume,

$$
\begin{aligned}
& \nu_{\mathrm{c}}(0)=\frac{1}{4}\left(J_{11}(0)+2 J_{12}(0)+J_{13}(0)\right)=\nu_{\mathrm{c}}^{0}(0)\left[1-\frac{2}{S} \frac{\delta_{1}}{\delta_{0}} \sum_{j=1}^{3} \varepsilon_{j}\right]+\sum_{i} \psi_{c i}(0) \varepsilon_{i}, \\
& \nu_{\mathrm{a}}\left(\boldsymbol{k}_{Z}\right)=\frac{1}{4}\left(J_{11}\left(\boldsymbol{k}_{Z}\right)-J_{13}\left(\boldsymbol{k}_{Z}\right)\right)=\nu_{\mathrm{a}}^{0}\left(\boldsymbol{k}_{Z}\right)\left[1-\frac{2}{S} \frac{\delta_{1}}{\delta_{0}} \sum_{j=1}^{3} \varepsilon_{j}\right]+\sum_{i} \psi_{a i}\left(\boldsymbol{k}_{Z}\right) \varepsilon_{i},
\end{aligned}
$$

are the eigenvalues of Fourier transforms of the long-range interaction matrices;

$$
D^{\mathrm{f}}=\cosh 2 z^{\mathrm{f}}+4 b \cosh z^{\mathrm{f}}+2 a+d, \quad D^{\mathrm{a}}=\cosh 2 z^{\mathrm{a}}+4 b \cosh z^{\mathrm{a}}+a+d+1 ;
$$




$$
\begin{aligned}
& z^{\mathrm{f}}=\frac{1}{2} \ln \frac{1+\eta^{\mathrm{f}}}{1-\eta^{\mathrm{f}}}+\beta \nu_{\mathrm{c}}(0) \eta^{\mathrm{f}}, \quad z^{\mathrm{a}}=\frac{1}{2} \ln \frac{1+\eta^{\mathrm{a}}}{1-\eta^{\mathrm{a}}}+\beta \nu_{\mathrm{a}}\left(\boldsymbol{k}_{Z}\right) \eta^{a}, \\
& a=\exp (-\beta \varepsilon), \quad b=\exp (-\beta w), \quad d=\exp \left(-\beta w_{1}\right) .
\end{aligned}
$$

The order parameter and lattice strains are to be found from

$$
\eta^{\mathrm{f}, \mathrm{a}}=\frac{1}{D^{\mathrm{f}, \mathrm{a}}}\left(\sinh 2 z^{\mathrm{f}, \mathrm{a}}+2 b \sinh z^{\mathrm{f}, \mathrm{a}}\right), \quad-p_{i}=\sum_{j} c_{i j} \varepsilon_{j},
$$

$c_{i j}$ are the elastic constants of the whole crystal; the first equation of (3) was obtained by minimizing the thermodynamic potential with respect to $\eta$.

The temperature of the first order phase transition can be determined from the following condition on the values of the thermodynamic potential

$$
g\left(\eta^{\mathrm{f}}\left(\text { or } \eta^{\mathrm{a}}\right), T_{\mathrm{C}}\left(\text { or } T_{\mathrm{N}}\right), p\right)=g\left(0, T_{\mathrm{C}}\left(\text { or } T_{\mathrm{N}}\right), p\right) .
$$

\section{The fitting procedure}

All the theory parameters were chosen such that the best fit to the pressure dependence of transition temperatures was obtained.

The parameters $\varepsilon^{0}, w^{0}, \nu_{\mathrm{c}}^{0}(0)$ and $\nu_{\mathrm{a}}\left(\boldsymbol{k}_{Z}\right)$, relevant to unstrained crystals, have been found earlier in $[9,11,12]$.

The ratio $\delta_{1} / \delta_{0}$ describing the rate of the pressure changes in the D-site distance is the only theory parameter different for hydrostatic and uniaxial pressures. For all crystals and pressures, we treat $\delta_{1} / \delta_{0}$ as a free parameter.

The contribution of lattice strains to the pressure dependence of the Slater energies can be neglected $\left(\delta_{i j}=0\right)$, so the latter is caused mainly by the pressure changes in the D-site distance $\delta$.

Unlike the Slater energies, the parameters of the long-range interactions are essentially influenced by the lattice strains. To estimate the values of the deformation potentials $\psi_{c j}(0)$ and $\psi_{a j}\left(\boldsymbol{k}_{Z}\right)$, which describe this influence, we use the fact that, loosely speaking, the dipole-dipole part of the long range interactions, and the part which describes the lattice mediated interactions are proportional to $a^{-3}$ and $a^{-6}$, respectively [5]. The best fit to the experimental dependence of the transition temperature of $\mathrm{KD}_{2} \mathrm{PO}_{4}$ on hydrostatic pressure is obtained if

$$
2 \psi_{c 1}(0)+\psi_{c 3}(0) \frac{\sum_{j} S_{3 j}}{\sum_{j} S_{1 j}} \simeq-8 \nu_{\mathrm{c}}^{0}(0)
$$

at $T>T_{\mathrm{C}}$. For the other crystals $\psi_{c 1}(0)$ or $\psi_{a 1}\left(\boldsymbol{k}_{Z}\right)$ can be set consistently by

$$
\frac{\psi_{c 1}(0)\left[\mathrm{or} \psi_{a 1}\left(\boldsymbol{k}_{Z}\right)\right]\left(\mathrm{MeD}_{2} \mathrm{XO}_{4}\right)}{\psi_{c 1}(0)\left(\mathrm{KD}_{2} \mathrm{PO}_{4}\right)}=\frac{\nu_{\mathrm{c}}^{0}(0)\left[\mathrm{or} \nu_{\mathrm{a}}^{0}\left(\boldsymbol{k}_{Z}\right)\right]\left(\mathrm{MeD}_{2} \mathrm{XO}_{4}\right)}{\nu_{\mathrm{c}}^{0}(0)\left(\mathrm{KD}_{2} \mathrm{PO}_{4}\right)}
$$

whereas $\psi_{c 3}(0)\left[\right.$ or $\left.\psi_{a 3}\left(\boldsymbol{k}_{Z}\right)\right]$ can be found from equation (5). 
A detailed description of the scheme of setting the values of elastic constants is given elsewhere $[7,8]$. As the first approximation, we took the available experimental values of $c_{i j}$ compiled in [13].

The values of the theory parameters yielding the best fit of theoretical dependencies of transition temperature on the pressure to experimental data are given in table 1 . Values of deuteration $x$ for $\mathrm{K}\left(\mathrm{H}_{1-x} \mathrm{D}_{x}\right)_{2} \mathrm{PO}_{4}$ crystals are nominal.

Table 1. The theory parameters for the crystals considered.

\begin{tabular}{|c|c|c|c|c|c|c|c|c|c|c|}
\hline \multirow[t]{2}{*}{ crystal } & $T_{\mathrm{C} 0}$ & $\partial T_{\mathrm{C}} / \partial p$ & $\delta_{1} / \delta_{0} \cdot 10^{3}$ & $\psi_{1}^{-} \psi_{2}^{-}$ & $\psi_{3}^{-}$ & $\psi_{1}^{+}$ & $\psi_{3}^{+}$ & $\varepsilon^{0}$ & $w^{0}$ & $\nu^{0}$ \\
\hline & $(\mathrm{K})$ & $(\mathrm{K} / \mathrm{kbar})$ & $\left(\mathrm{kbar}^{-1}\right)$ & \multicolumn{4}{|c|}{$(\mathrm{K})$} & \multicolumn{3}{|c|}{$(\mathrm{K})$} \\
\hline $\mathrm{KD}_{2} \mathrm{PO}_{4}$ & 220 & $-2.0[14]$ & -6.4 & 130 & -560 & 120 & -560 & 92.0 & 830 & 38.0 \\
\hline $\mathrm{KD}_{2} \mathrm{PO}_{4}$ & 220 & $-3.0[15]$ & -7.6 & 130 & -560 & 120 & -560 & 92.0 & 830 & 38.0 \\
\hline $\mathrm{K}\left(\mathrm{H}_{0.13} \mathrm{D}_{0.87}\right){ }_{2} \mathrm{PO}_{4}$ & 210 & $-12.5[16]$ & -33.5 & 120100 & -545 & 110 & -545 & 87.6 & 785 & 37.05 \\
\hline $\mathrm{K}\left(\mathrm{H}_{0.16} \mathrm{D}_{0.84}\right)_{2} \mathrm{PO}_{4}$ & 208 & $-3.0[15]$ & -9.8 & 110 & -545 & 100 & -545 & 87.6 & 785 & 36.0 \\
\hline $\mathrm{RbD}_{2} \mathrm{PO}_{4}$ & 207.3 & $-3.7[17]$ & -10.7 & 110 & -450 & 100 & -450 & 95.9 & 828 & 29.9 \\
\hline $\mathrm{KD}_{2} \mathrm{AsO}_{4}$ & 159.7 & $-1.6[18]$ & -6.0 & 80 & -220 & 70 & -220 & 73.0 & 800 & 21.6 \\
\hline $\mathrm{RbD}_{2} \mathrm{AsO}_{4}$ & 169.8 & $-2.7[18]$ & -8.5 & 100 & -210 & 90 & -210 & 77.8 & 795 & 23.3 \\
\hline $\mathrm{ND}_{4} \mathrm{D}_{2} \mathrm{PO}_{4}$ & 235.0 & $-1.4[19]$ & -4.9 & 310290 & -500 & 290 & -560 & 77.0 & 709 & 85.75 \\
\hline $\mathrm{ND}_{4} \mathrm{D}_{2} \mathrm{AsO}_{4}$ & 286.3 & $-1.4[20]$ & -4.4 & 380360 & -680 & 370 & -680 & 105.0 & 810 & 103.65 \\
\hline
\end{tabular}

\begin{tabular}{|c|c|c|c|c|c|c|c|c|c|c|}
\hline \multirow[t]{2}{*}{ crystal } & $c_{11}^{+}$ & $c_{12}^{+}$ & $c_{13}^{+}$ & $c_{33}^{+}$ & $c_{11}^{-}$ & $c_{12}^{-}$ & $c_{13}^{-}$ & $c_{22}^{-}$ & $c_{23}^{-}$ & $c_{33}^{-}$ \\
\hline & \multicolumn{10}{|c|}{$\left(10^{5} \mathrm{bar}\right)$} \\
\hline $\mathrm{KD}_{2} \mathrm{PO}_{4}$ & 6.14 & -0.71 & 1.05 & 4.82 & 6.14 & -0.71 & 1.0 & 6.14 & 1.1 & 4.3 \\
\hline $\mathrm{K}\left(\mathrm{H}_{0.13} \mathrm{D}_{0.87}\right)_{2} \mathrm{PO}_{4}$ & 6.93 & -0.78 & 1.22 & 5.45 & 6.8 & -0.78 & 1.0 & 6.99 & 1.0 & 5.3 \\
\hline $\mathrm{RbD}_{2} \mathrm{PO}_{4}$ & .85 & -0.1 & 1.3 & 5.2 & 6.85 & -0.1 & 1.3 & 6.85 & 1.2 & 5.2 \\
\hline $\mathrm{KD}_{2} \mathrm{AsO}_{4}$ & 6.5 & 0.8 & 1.36 & 4.9 & 6.6 & 0.8 & 1.33 & 6.5 & 1.37 & 4.9 \\
\hline $\mathrm{RbD}_{2} \mathrm{AsO}_{4}$ & 4.9 & -1.92 & 0.48 & 3.8 & 4.98 & -1.92 & 0.48 & 4.978 & 0.48 & 3.8 \\
\hline $\mathrm{ND}_{4} \mathrm{D}_{2} \mathrm{PO}_{4}$ & 6.28 & 0.39 & 1.9 & 3.25 & 6.28 & 0.39 & 1.6 & 6.28 & 1.59 & 3.25 \\
\hline $\mathrm{ND}_{4} \mathrm{D}_{2} \mathrm{AsO}_{4}$ & 6.4 & 0.9 & 2.4 & 3.85 & 6.4 & 0.9 & 2.4 & 6.3 & 2.2 & 3.85 \\
\hline
\end{tabular}

a) $\nu^{0}=\nu_{\mathrm{c}}^{0}(0)$ and $\psi_{i}=\psi_{c i}(0)$ for ferroelectrics; $\nu^{0}=\nu_{\mathrm{a}}^{0}\left(\boldsymbol{k}_{Z}\right)$ and $\psi_{i}=\psi_{a i}\left(\boldsymbol{k}_{Z}\right)$ for antiferroelectrics. $\psi_{i}^{-}$and $\psi_{i}^{+}$are the values of the deformation potentials below and above transition point, respectively.

b) values of $\partial T_{\mathrm{C}} / \partial p$ and $\delta_{1} / \delta_{0}$ for $\mathrm{K}\left(\mathrm{H}_{0.13} \mathrm{D}_{0.87}\right)_{2} \mathrm{PO}_{4}$ correspond to $p=-\sigma_{3}$.

c) difference between $c_{i j}$ of $\mathrm{K}\left(\mathrm{H}_{0.13} \mathrm{D}_{0.87}\right)_{2} \mathrm{PO}_{4}$ and $\mathrm{K}\left(\mathrm{H}_{0.16} \mathrm{D}_{0.84}\right)_{2} \mathrm{PO}_{4}$ is neglected.

In figures $1 \mathrm{a}$ and $1 \mathrm{~b}$ we plot the dependence of the phase transition temperature of the six $\mathrm{MeD}_{2} \mathrm{XO}_{4}\left(\mathrm{Me}=\mathrm{K}, \mathrm{Rb}, \mathrm{ND}_{4}, \mathrm{X}=\mathrm{P}, \mathrm{As}\right)$ crystals on hydrostatic pressure along with the experimental points. Naturally, a perfect fit of theoretical results to the experimental data is obtained. The $T_{\mathrm{C}}$ vs uniaxial pressure $p=-\sigma_{3}$ line for $\mathrm{K}\left(\mathrm{H}_{0.13} \mathrm{D}_{0.87}\right)_{2} \mathrm{PO}_{4}$ is presented in figure 1c. A rapid decrease in transition temperature with the uniaxial pressure $p=-\sigma_{3}$ was detected experimentally [16]; to describe it, a negative value of $\delta_{1} / \delta_{0}$ was used in calculations. The fact that variation of $T_{\mathrm{C}}$ with uniaxial pressure is more pronounced than with hydrostatic is understandable, since the uniaxial pressure deforms the crystal stronger than the hydrostatic pressure does. The unexpected outcome of the fitting process is that the uniaxial pressure $p=-\sigma_{3}$ shortens the hydrogen bonds and D-site distances $\left(\delta_{1} / \delta_{0}<0\right)$ : one would rather expect the pressure applied along the $c$-axis to expand the D-bonds lying in 
the $a b$-plane. One of the possible explanations of this shortening is that $p=-\sigma_{3}$ pressure flattens $\mathrm{PO}_{4}$ tetrahedra along the $c$-axis, thereby enlarging their projection on the $a b$-plane and reducing the distances between oxygens of different $\mathrm{PO}_{4}$ groups. However, this conjecture should await an experimental verification.
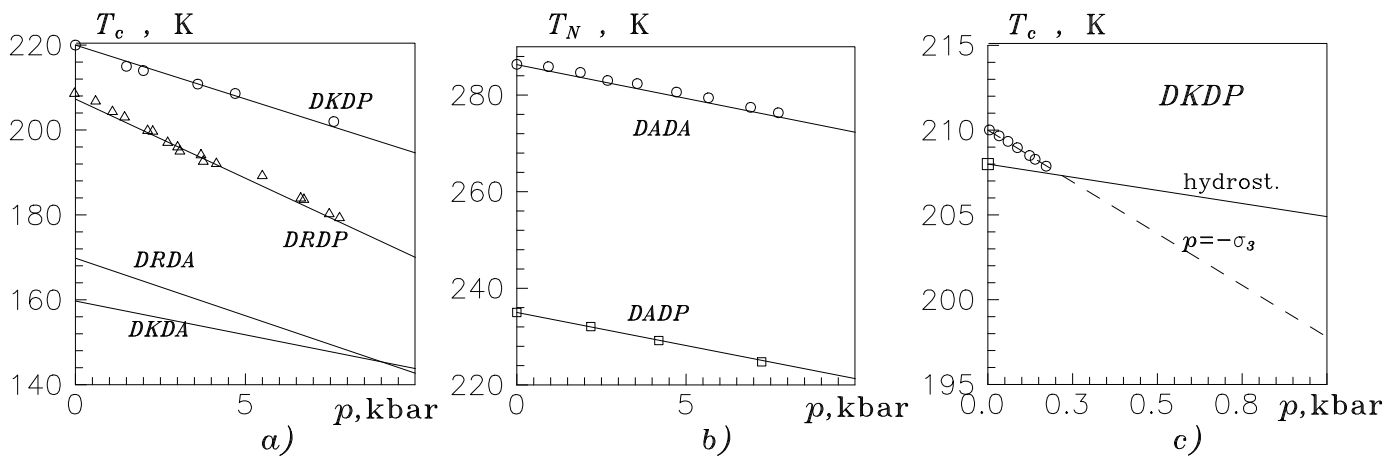

Figure 1. Pressure dependence of transition temperature: a) $\circ$, [15] $-\mathrm{KD}_{2} \mathrm{PO}_{4}$, $\triangle,[17]-\mathrm{RbD}_{2} \mathrm{PO}_{4}$ (tetragonal), $\mathrm{KD}_{2} \mathrm{AsO}_{4}, \mathrm{RbD}_{2} \mathrm{AsO}_{4}$; b) $\square$, [19] - $\mathrm{ND}_{4} \mathrm{D}_{2} \mathrm{PO}_{4}$, and $\circ$, [20] $\left.-\mathrm{ND}_{4} \mathrm{D}_{2} \mathrm{AsO}_{4} ; \mathrm{c}\right) \mathrm{K}\left(\mathrm{H}_{1-x} \mathrm{D}_{x}\right)_{2} \mathrm{PO}_{4}$ with nominal values of $x: 0.87$ $\left(T_{\mathrm{C} 0}=210 \mathrm{~K}\right)-\mathrm{O},[16]$, dashed line; $0.84\left(T_{\mathrm{C} 0}=208 \mathrm{~K}\right)-\square$, [15], solid line.

Universality of the transition temperature vs D-site distance dependence is clearly manifest in figure 2 . The values of $\delta$ are calculated using the values of the ratio $\delta_{1} / \delta_{0}$ from table 1 , which provide the correct slopes $\partial T_{\mathrm{C}} / \partial p$ and assuming a universal $T_{\mathrm{C} 0}(\delta)$ dependence for all these crystals at atmospheric pressure. As one can see, the points $T_{\mathrm{C}}(\delta)$ and $T_{\mathrm{N}}(\delta)$ plotted for several ferroelectric and antiferroelectric crystals of $\mathrm{KH}_{2} \mathrm{PO}_{4}$ family, strained either by hydrostatic or uniaxial pressure, lie on a single line. Therefore, the proton ordering model not only describes the universal $T_{\mathrm{C}}$ vs $\delta$ dependence [3] observed in $\mathrm{KD}_{2} \mathrm{PO}_{4}$ and $\mathrm{ND}_{4} \mathrm{D}_{2} \mathrm{PO}_{4}$ under hydrostatic pressure, but also predicts that this dependence is also obeyed by the other crystals of the family strained by hydrostatic pressure as well as by the $\mathrm{K}\left(\mathrm{H}_{0.13} \mathrm{D}_{0.87}\right){ }_{2} \mathrm{PO}_{4}$ strained by uniaxial pressure $p=-\sigma_{3}$. This fact again emphasizes the importance of the D-site distance in the phase transition in hydrogen bonded crystals and supports our assumption that pressure $p=-\sigma_{3}$ reduces $\delta$.

\section{Concluding remarks}

We presented a unified approach enabling us to describe the effects of hydrostatic and uniaxial pressures on the phase transition in deuterated ferroelectrics and antiferroelectrics of KDP family. We also studied the pressure influence on dielectric properties in these crystals. Results of the studies will be published elsewhere.

The calculations performed within the proton ordering model in the framework of the four particle cluster approximation confirm the possibility of the proton ordering model to describe the behaviour of KDP-type crystals under external pressure. The proposed scheme of choosing the theory parameters makes it possible to describe the influence of different pressures on a transition temperature of the crystals. The main 


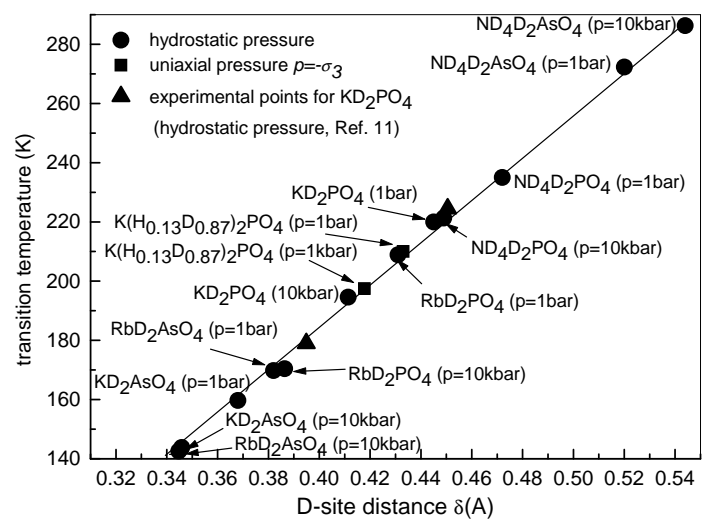

Figure 2. Transition temperature vs D-site distance dependence for several crystals of the $\mathrm{KH}_{2} \mathrm{PO}_{4}$ family.

parameter which determines the pressure dependencies of the transition temperature (and, as we show elsewhere, of spontaneous polarization and static dielectric permittivities) is the ratio $\delta_{1} / \delta_{0}$, which is the rate of the pressure-induced changes in the D-site distance. Our calculations show that the universality of the transition temperature vs D-site distance dependence observed experimentally in some of the crystals deformed by hydrostatic pressure is also obeyed by the other crystals of the family as well as under the uniaxial pressure $p=-\sigma_{3}$. The theory predicts that this uniaxial pressure should shorten the D-site distance, even though it is applied along the axis perpendicular to the plane in which the hydrogen bonds lie. Further structural measurements of the hydrostatic and, especially, uniaxial pressure effects on the KDP family crystals will enable us to ascertain the values of the theory parameters and verify its predictions.

\section{Acknowledgements}

This work was supported by the Foundation for Fundamental Investigations of the Ukrainian Ministry in Affairs of Science and Technology, project No 2.04/171.

\section{References}

1. Tominaga Y. // Ferroelectrics, 1983, vol. 52, p. 91-100.

2. Ichikawa M., Motida K., Yamada N. // Phys. Rev. B., 1987, vol. 36, No. 1, p. 874-876.

3. Piltz R.O., McMahon M.I., Nelmes R.J. // Ferroelectrics, 1990, vol. 108, p. 271-276.

4. Stasyuk I.V., Biletskii I.N. // Bull. Ac. Sci. USSR, Phys. Ser., 1983, vol. 4, p. 79-82.

5. Blinc R, Žekš B. // Helv. Phys. Acta, 1968, vol. 41, p. 701-706.

6. Torstveit S. // Phys. Rev. B, 1979, vol. 20 , No. 11, p. 4431-4441.

7. Stasyuk I.V., Levitskii R.R., Moina A.P. // Phys. Rev. B, 1999, vol. 59, No. 13, p. $8530-8540$.

8. Levitskii R.R., Moina A.P. Influence of external pressure on phase transitions and dielectric properties of KDP family crystals. Preprint of the Institute for Condensed Matter Physics, ICMP-98-19E, Lviv, 1998, 24 p. 
9. Vaks V.G., Zein N.E., Strukov B.A. // Phys. Stat. Solidi (a), 1975, vol. 30, p. 801-819.

10. Nelmes R.J. // Ferroelectrics, 1987, vol. 71, p. 87-123.

11. Levitskii R.R., Zachek I.R., Mits Ye.V. Thermodynamics and longitudinal relaxation of ferroelectrics $\mathrm{K}\left(\mathrm{H}_{1-x} \mathrm{D}_{x}\right)_{2} \mathrm{PO}_{4}$. Preprint of the Institute for Theoretical Physics, ITP-87-114R, Kiev, 1987, 48 p. (in Russian).

12. Levitskii R.R., Mits Ye.V., Zachek I.R. Dynamics and some thermodynamic properties of $\mathrm{ND}_{4} \mathrm{D}_{2} \mathrm{PO}_{4}$-type antiferroelectrics. Preprint of the Institute for Theoretical Physics, ITF-81-137R, Kiev, 1982, 40 p. (in Russian).

13. Landolt-Börnstein. Numerical Data and Functional Relationships in Science and Technology. New Series. Group III, subvolume b. Springer-Verlag Berlin-Heidelberg, New York, 1982.

14. Zhukov S.G., Kul'bachinskii V.A., Smirnov P.S., Strukov B.A., Chudinov S.H. // Bull. Ac. Sci. USSR. Phys. Ser., 1985, vol. 49, No. 2, p. 40-42.

15. Samara G.A. // Ferroelectrics, 1979, vol. 22, p. 925-936.

16. Stadnik N.I., Romanyuk N.A., Chervonyj R.G. // Opt. Spectrosk., 1998, vol. 84, p. 273.

17. Gesi K., Ozawa K., Osaka T., Makita Y. // J. Phys. Soc. Jap., 1992, vol. 61, No. 1, p. $342-347$.

18. Spillman W.B., Leung R.C., Tornberg N.E., Lowndes R.P. // Ferroelectrics, 1977, vol. 17, p. 383-385.

19. Skalyo J., Jr., Frazer B.C., Shirane G., Daniels W.B. // J. Phys. Chem. Solids, 1969, vol. 30, p. 2045-2051.

20. Gesi K., Ozawa K. // J. Phys. Soc. Jap., 1984, vol. 53, No. 12, p. 4405-4412.

\title{
Температури переходу деформованих кристалів сім'ї KDP
}

\author{
Р.Р.Левицький ${ }^{1}$, А.П.Моїна ${ }^{1}$, І.Р.Зачек ${ }^{2}$ \\ 1 Інститут фізики конденсованих систем НАН України, \\ 79011 Львів, вул. Свєнціцького, 1 \\ 2 Державний університет "Львівська Політехніка", \\ Україна, 290000, Львів. вул. Бандери, 13
}

Отримано 4 жовтня 1998 р.

У наближенні чотиричастинкового кластера для моделі протонного впорядкування досліджуються ефекти, викликані зовнішніми тисками, що не понижують симетрії кристалів, на дейтеровані сегнетоелектрики і антисегнетоелектрики сім'ї $\mathrm{KH}_{2} \mathrm{PO}_{4}$. Показано, що експериментально виявлена для деяких з цих кристалів, деформованих гідростатичним тиском, універсальна залежність температур переходу від віддалі між можливими положеннями дейтрона на зв'язку, поширюється також і на інші кристали цієї сім'ї, що можуть бути деформовані і одновісним тиском.

Ключові слова: KDP, тиск, фазовий перехід.

PACS: $77.84 . F$ 